\title{
ANALYSIS OF DIFFERENT HEAT TRANSFER AUGMENTATION CONFIGURATIONS OF HEAT EXCHANGERS FOR INDUSTRIAL WASTE HEAT RECOVERY APPLICATION
}

\author{
Jyoti \\ PG Scholar, Rajasthan Technical University, \\ Kota, Rajasthan, India \\ Mahendra Lalwani \\ Associate Professor, Rajasthan Technical University, \\ Kota, Rajasthan, India

\section{Dr. Sanjeev Mishra} \\ Professor, Rajasthan Technical University, \\ Kota, Rajasthan, India
}

\begin{abstract}
Energy Deficiency can be reduce by use of waste and available forms of energy (Non-conventional) to produce electricity or utilize them to reduce usage of other power absorbing devices as the world is facing energy crisis and as our fuel resources are depleting very fast. In Conventional Power Producing methods wasted heat can be recovered in Boiler accessories like Economizers and Air Preheaters with less effectiveness. Current work is investigation of various aspects of convective heat transfer enhancement using Pin Fins, Corrugated Tubes and Twisted Tapes. The basic methods used to enhance the heat transfer by simultaneous increase of heat transfer surface area as well as the heat transfer coefficient. The method is carried out as on combination of Pin Fins, Corrugated Tubes and Twisted Tape as elements for the heat transfer enhancement, Investigations of a double-pipe Pin Fin heat exchanger were carried out. The heat transfer and pressure drop results for the Pin Fin and Corrugated tube heat exchanger were compared with the results for a smooth-pipe heat exchanger. It was found that by a direct comparison of Nusselt number Nu and Euler number Eu, conclusion regarding the relative performances could be made. Geometric parameters are considered, Ratio of Spacing between the fins and diameter of Pin Fin and the Ratio of Corrugated Tube diameter and diameter of corrugation. Heat transfer depends on numbers of Pins and spacing between pins. In this study Heat transfer enhancement is found to be about 5-15\% for Pin Fin and 6-23\% for Corrugated Tube with Twisted Tape. This Improvement will effectively improvise the overall efficiency of Conventional and Non-Conventional Power Plants.
\end{abstract}


Key words: Pin Fin, Heat Exchanger, Nusselt Number(Nu), Euler Number(Eu), Convection.

Cite this Article: Jyoti, Mahendra Lalwani and Dr. Sanjeev Mishra, Analysis of Different Heat Transfer Augmentation Configurations of Heat Exchangers for Industrial Waste Heat Recovery Application, International Journal of Advanced Research in Engineering and Technology, 10 (4), 2019, pp 22-31.

http://iaeme.com/Home/issue/IJARET?Volume=10\&Issue $=4$

\section{INTRODUCTION}

Energy crisis due to oil shortage also the fast depletion of fossil fuels serve to focus attention upon energy problems the study of exploring new and renewable energy sources and to catalogue steps necessary for energy conservation. While fresh power sources such as solar, wind, biomass and biogas have been studied due importance should be given to the recovery of heat energy available in the industrial exhaust. Energy preservation plays an important part in the country's financial development. About $37 \%$ of the total commercial energy consumption of India is made by industries. A major portion of this is consumed to produce process heat [7]. The efficiency of furnaces and heat equipment's available in India is less than $50 \%$. This means that more than $50 \%$ of heat is wasted in exhaust gas. If this heat is recovered effectively a substantial amount of fuel can be saved.

Table 1 High and Medium-Temperature Waste Heat [3]

\begin{tabular}{|c|c|c|}
\hline Type of Device & Location & Temperature $^{\circ} \mathbf{C}$ \\
\hline Nickel refining furnace & Furnace Exit & $1350-1650$ \\
Aluminium refining furnace & Furnace Exit & $650-760$ \\
Zinc refining furnace & Furnace Exit & $760-1100$ \\
Copper refining furnace & Furnace Exit & $760-820$ \\
Steel heating furnace & Furnace Exit & $930-1040$ \\
Copper furnace & Furnace Exit & $900-1100$ \\
Open hearth furnace & Furnace Exit & $650-700$ \\
Cement kiln (dry process) & Kiln Exit & $620-730$ \\
Glass melting furnace & Furnace Exit & $980-1540$ \\
Hydrogen plants & Furnace Exit & $650-980$ \\
Solid waste incinerators & Incinerator Exit & $650-980$ \\
Fume incinerators & Incinerator Exit & $650-1430$ \\
\hline
\end{tabular}

Waste heat has been defined as heat which is rejected from a process at a temperature enough above the ambient temperature to permit the extraction of additional value from it. There are waste heat greater than $650^{\circ} \mathrm{C}$ and waste heat in between $230^{\circ} \mathrm{C}$ to $650^{\circ} \mathrm{C}$ [3]. Different temperature waste heat can be used to produce steam which can be utilized for process or power generation $[4,5]$. Tables 1 show the temperature level of the waste heat streams in different Devices and Locations. The following industries/systems are commonly believed to have the most potential for waste heat recovery. Petroleum refining, Steel, Aluminium, Paper, Olefins and derivatives, Textiles, Cement, Glass, Boilers, [3].

Some typical uses of waste heat are as follows.

i. To produce steam for process heat application or for generation of electrical and mechanical power

ii. For preheating feed water 
iii. To heat air for drying purposes.

iv. To produce refrigeration

v. For space heating and domestic water heating.

The use of finned tubes in heat exchanging devices results into enhancement in Heat transfer rate. Wei Wang et al [1] (2017) studied Multi-objective optimization of turbulent heat transfer flow in novel outward helically corrugated tubes. If the heat transfer performance is dominant, higher Re and H1/D with a lower $\mathrm{pl} / \mathrm{D}$ are better for heat exchangers designed. An equilibrium interval was obtained on the Pareto front at which the optimization values of $\mathrm{Nu}$, f, Re, and PEC correspond to 87.55-108.81, 1595.88-2502.69, and 1.08-1.04, respectively. The Reynolds number ( $\mathrm{Re}$ ) has the most effect on Nusselt number $(\mathrm{Nu})$. Hamed Sadighi Dizaji et al [2] (2016) Investigated distinct arrangements of concave and convex type of corrugated tubes Exergy loss due to simultaneous employing of corrugated tubes as the inner and outer tube (shell) of a shell and tube heat exchanger are also investigated. Corrugations create secondary flows through the heat exchanger. Xu Jin et al [3] the increase of energy demand and environmental awareness, it becomes an inexorable trend to develop and utilize renewable energy and to increase the proportion of clean energy in end use energy. The development of power grid in future should not only consider power demand but also accommodate large-scale renewable energy. Gómez M.A. et al [4] (2018) Investigated The natural convection to solve the fluid movements that occur by natural convection, a fitting method is used to calculate the heat transfer of the corrugated surface in a smooth coil. Comparison of Experimentation and Numerical investigation shows 33.33\% good Agreement. Hamed Sadighi Dizaji et al [5] (2015) have experimentally investigated pressure drop, heat transfer and effectiveness of double pipe heat exchanger made of corrugated outer and inner tubes. J.I. Córcoles-Tendero et al [6] (2018) have experimentally analyzed the effect of spirally corrugation in a simple tube on the heat transferred and friction factor using numerical simulations. For the smooth and corrugated tubes, stainless steel tubes with an inner diameter of $18 \mathrm{~mm}$ and a wall thickness of $1 \mathrm{~mm}$ were used.

Fabio Bozzoli et al [7] (2016) investigated the effect of wall corrugation on local convective heat transfer in coiled tubes. More Pressure drop occurs at corrugated surface compare to smooth pipe but heat transfer rate increases as surface area increases in case of corrugations. Norris and Spofford [8] (1942) derived the first basic heat transfer and flowfriction data for Pin Fin surfaces. By use of the perimeter as the length scale, they could approximately represent the heat transfer data with a single curve for a single plane, single cylinder, various strip fins and Pin Fins. They also included in their tests an in-line Pin Fin arrangement with pin diameters of $0.5 \mathrm{~mm}$ and $1 \mathrm{~mm}$ and a pin length of $\sim 19 \mathrm{~mm}$. Kays [9] (1955) performed probably the most extensive study of Pin Fins as elements for heat transfer enhancement. With some problems which may be encountered with Pin Fin heat exchangers such as the pin vibration and the tendency of the flow to become completely laminar if the pins are in an in-line arrangement and too close to each other.

\subsection{Scope of the Present Work}

The present investigation has been carried out in order to

a. To compare the performance of the Smooth Tube Heat Exchanger with and without Corrugated Tube Heat Exchanger.

b. To determine an equation for the local temperature, local heat transfer coefficient around the finned tube and heat recovery by regression analysis.

c. To compare the performance of the Smooth Tube Heat Exchanger with and without 


\section{WASTE HEAT RECOVERY BY HEAT EXCHANGER}

Heat exchangers are widely used in various industrial, transportation, or domestic applications such as thermal power plants, means of transport, heating and air conditioning systems, electronic equipment and space vehicles. In all these applications, improvements in the efficiency of heat exchangers can lead to substantial cost, space and materials savings. Therefore, considerable research work has been done in the past to seek effective ways to increase the efficiency of heat exchangers [1]. Effective heat transfer enhancement techniques have been reported. However, in the present work only the single-phase forced convection enhancement techniques have been considered. The heat transfer enhancement methods reported in publications be systemized in many forms but primarily they may be grouped as passive and active enhancement methods.

\section{PREPARATION OF PROPOSED MODELS}

Ansys is the finite element analysis code widely used in computer aided engineering (CAE) field. ANSYS software help us to construct computer models of structure, machine, components or system, apply operating loads and other design criteria and study physical Response such as stress level temperature distribution, pressure [5].

Some assumptions are used such as the flow through the tube is turbulent and incompressible. In the present numerical solution, the steady incompressible Navier-Stokes and the turbulence ( $\mathrm{k}-\omega$ realizable wall including viscous heating) equations were discretized using the finite volume technique. To evaluate the pressure field, the pressure-velocity coupling and SIMPLE algorithm is selected. Also the solution convergence is met in the range of 297-389 iterations when the difference between normalized residual of the algebraic equation and the prescribed value is less than 10-3 for momentum, continuity and turbulence equations and 10-6 for energy equation. Results Analysis in CFD Post

Following are general steps involved

- Model making using Design Modeler

- Meshing using ICEM CFD

- Setup of Solution

- Result

\subsection{Model Making using Design Modeler}

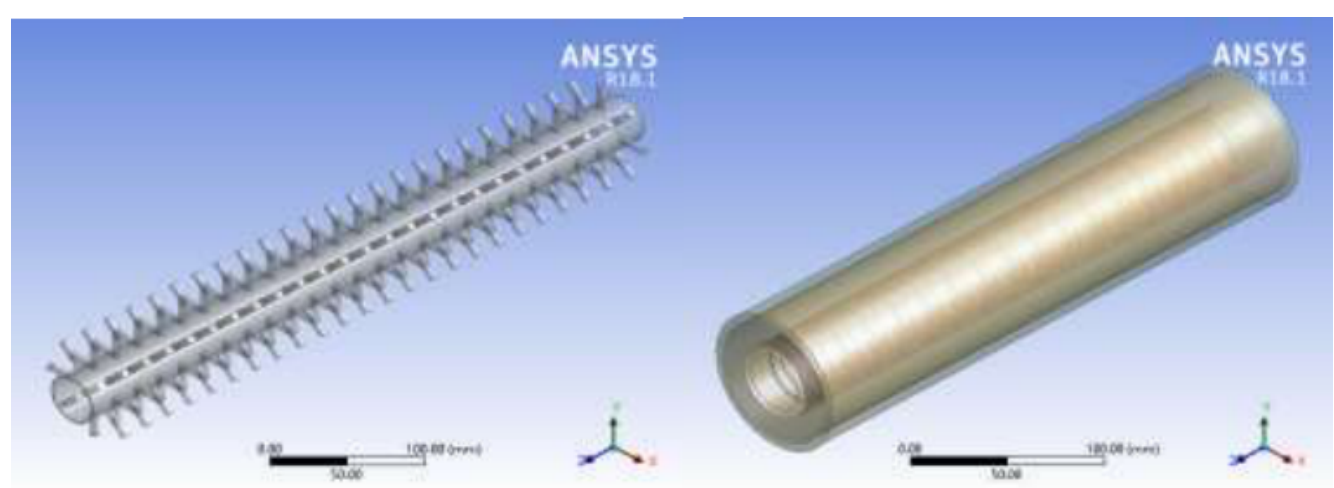

Figure 1 Pin fin heat exchanger inner tube. Tube in Tube counter flow heat exchanger

Meshing Details

Meshing was completed in Work-Bench Mesher. 
Element Type: Tetrahedrals + Hexahedrals + Prisms

Total Number of Elements: 8,380,000

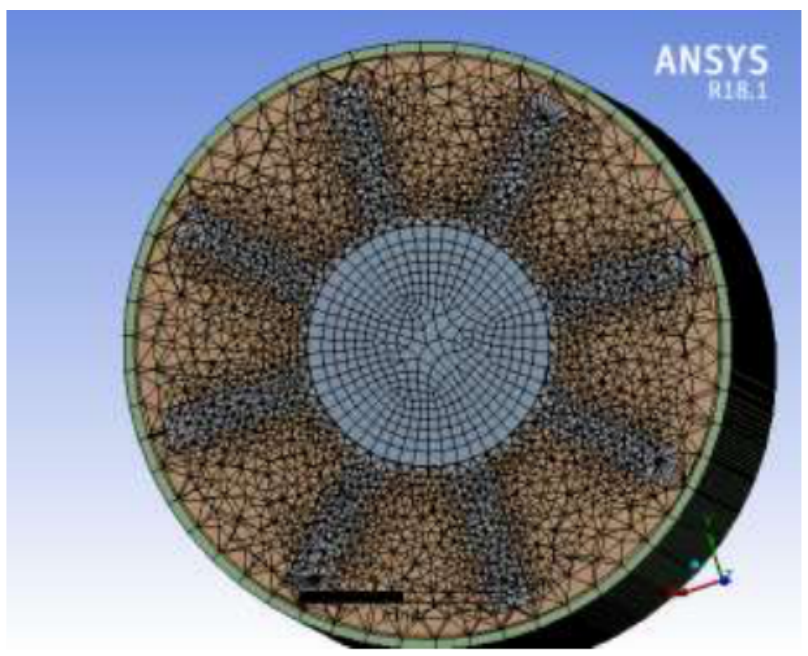

Figure 2 Meshing model

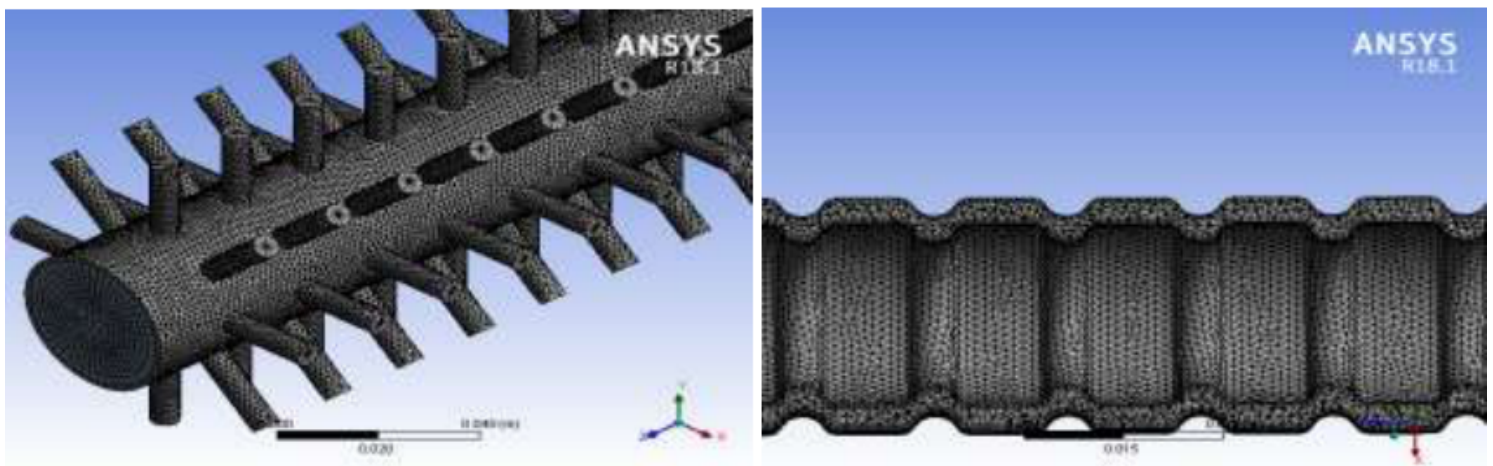

Figure 3 Meshing model Inner Tube OF Pin Fin and Corrugated Tubes

\subsection{Setting Up of Solution}

The Experimentation is setup in the Ansys 18.1 with variable mass flow inlet and with respect to that various Re value. The heat transfer is improved due to recirculation of Secondary flow.

\section{PIN FIN HEAT EXCHANGERS}

While seeking heat transfer enhancement, apart from the utilization of various surface enhancement elements, efforts have also been made to select an optimal flow arrangement within the heat exchanger in order to obtain the maximum advantage for a given heat exchanger configuration. The dimensions with non-dimensional ratio taken are shown in Table-II.

Table 2 Specifications of Samples Pin Fin HEX

\begin{tabular}{|l|l|l|l|l|l|l|}
\hline $\begin{array}{l}\text { Sr. } \\
\text { No. }\end{array}$ & Specimen & D $(\mathrm{mm})$ & $\mathrm{L}(\mathrm{mm})$ & $\begin{array}{l}\text { St } \\
\text { (Longitudinal) }\end{array}$ & $\begin{array}{l}\text { St } \\
\text { (Transverse) }\end{array}$ & St /Dia. \\
\hline 1 & Case-I & $6 \mathrm{~mm}$ & $500 \mathrm{~mm}$ & $11 \mathrm{~mm}$ & $18 \mathrm{~mm}$ & 1.8 \\
\hline 2 & Case-II & $6 \mathrm{~mm}$ & $500 \mathrm{~mm}$ & $15 \mathrm{~mm}$ & $18 \mathrm{~mm}$ & 2.5 \\
\hline 3 & Case-III & $6 \mathrm{~mm}$ & $500 \mathrm{~mm}$ & $11 \mathrm{~mm}$ & $24 \mathrm{~mm}$ & 3.8 \\
\hline 4 & Case-IV & $6 \mathrm{~mm}$ & $500 \mathrm{~mm}$ & $15 \mathrm{~mm}$ & $24 \mathrm{~mm}$ & 4.5 \\
\hline
\end{tabular}


The quantitative heat transfer and pressure drop characteristics of Pin Fin heat exchangers, are presented in terms of significant non-dimensional numbers in Fig.8 and Fig.9. Fig.8 clearly suggests that with a reduction in transverse pin spacing, the $\mathrm{Nu}$ increases over the entire range of $\mathrm{Re}$. The increase in $\mathrm{Nu}$ can be attributed to the increase in the wetted area, for smaller pin spacing's in the transverse direction. A similar behavior of $\mathrm{Nu}$ is observed also for variable pitch to the diameter However, with a decrease in pitch to the diameter

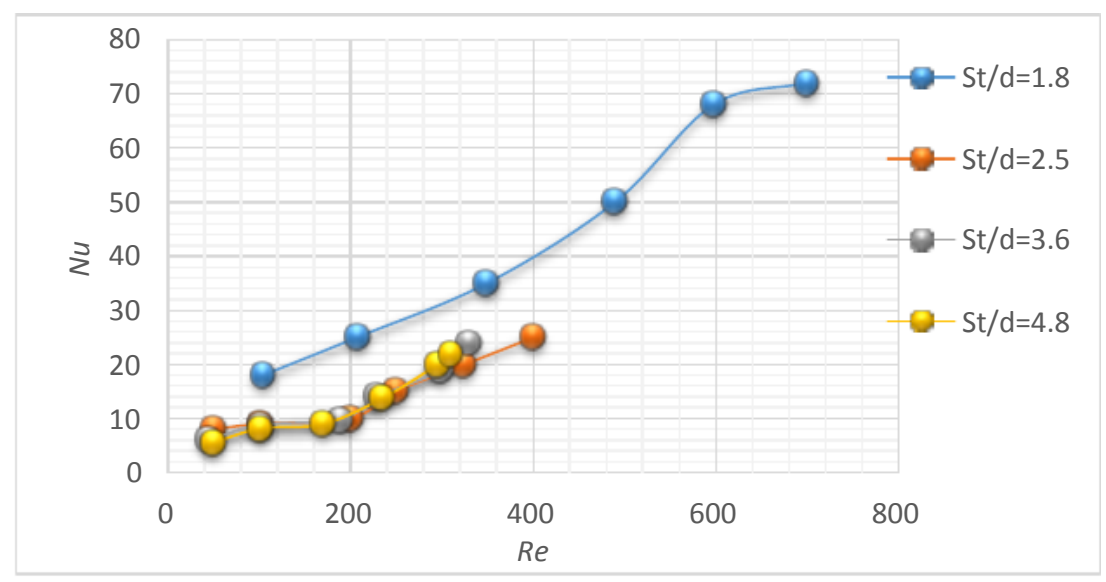

Figure $4 \mathrm{Nu}$ of the Pin Fin heat exchanger, in-line pin arrangement

$\mathrm{Nu}$ increases with a reduction in pitch to diameter ratio. The pitch to diameter ratio shows somehow rational behavior in response to the Nusselt number. This is because Nusselt number is calculated from a heat transfer coefficient that is evaluated with reference to the bare surface, which increases continuously with increase in pin length.

$$
E u=\frac{2 \Delta p}{\rho_{a} u_{a}^{2} N}
$$

Where Pressure drop $\Delta \mathrm{p}$ is calculated by output of the ansys analysis after convergence as shown in Fig. 4 whereas mean air velocity of flow is given in setup of solution. $\mathrm{N}$ is number of Pin Fins in a row.

However, Fig. 5 show that the behavior of Eu in response to changes in Re corresponding pin fin arrangement. A completely different behavior can be observed regarding the variation of $\mathrm{Eu}$ with pitch to diameter ratio. For the same configuration an increase of $\mathrm{Nu}$ with decreases in pitch to diameter ratio could be observed (Fig.4), this specific pin arrangement is likely to result in a very high heat exchanger performance. Fig. 6 shows the temperature variation with respect to the pin fin arrangement it clearly shows that pin fin easily improves heat transfer rate but also causes sort of rise in pressure drop this result into need of more pumping power to transfer fluid (Hot/Cold) from inlet to the outlet. The corrugated tube arrangement is in comparison to the pin fin arrangement is more suitable as the pressure drop is less. 


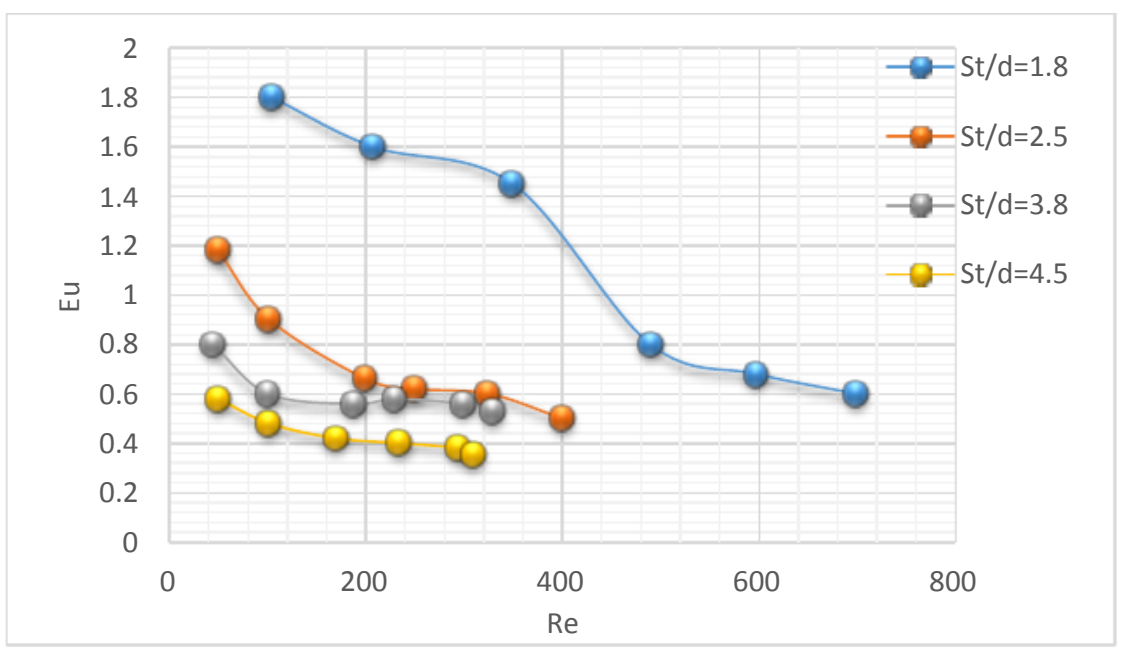

Figure $5 \mathrm{Eu}$ of Pin Fin heat exchanger with variation in pin fin configurations, in line pin arrangement

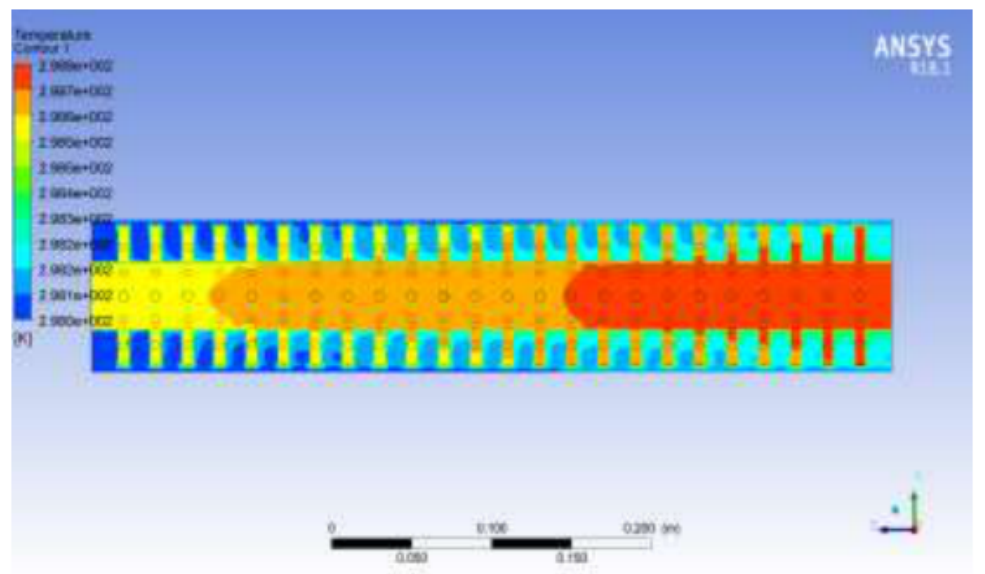

Figure 6 Temperature Contour of Pin Fins

\section{CORRUGATED TUBE HEAT EXCHANGERS}

The geometric parameters selected for corrugated tube heat exchanger is presented in Table-I. The quantitative heat transfer and pressure drop characteristics of Corrugated Tube heat exchanger, are presented in terms of significant non-dimensional numbers in Fig.3 and Fig.4.

Table 3 Specifications of Samples for Corrugated tube HEX

\begin{tabular}{|c|c|c|c|c|}
\hline $\begin{array}{c}\text { Sr. } \\
\text { No. }\end{array}$ & Specimen & Corrugation Dia. & L & $\begin{array}{c}\text { Longitudinal } \\
\text { Pitch }\end{array}$ \\
\hline 1 & Case-I & $5 \mathrm{~mm}$ & $340 \mathrm{~mm}$ & $20 \mathrm{~mm}$ \\
\hline 2 & Case-II & $5 \mathrm{~mm}$ & $340 \mathrm{~mm}$ & $30 \mathrm{~mm}$ \\
\hline 3 & Case-III & $7.5 \mathrm{~mm}$ & $340 \mathrm{~mm}$ & $20 \mathrm{~mm}$ \\
\hline 4 & Case-IV & $7.5 \mathrm{~mm}$ & $340 \mathrm{~mm}$ & $30 \mathrm{~mm}$ \\
\hline
\end{tabular}

It is observed from Fig. 3 that with an increase in corrugation diameter the $\mathrm{Nu}$ increases over the entire range of $\mathrm{Re}$. The increase in $\mathrm{Nu}$ can be attributed to the increase in the wetted area, for smaller corrugation diameter. A similar behavior of $\mathrm{Nu}$ is observed also for variable Longitudinal pitch However, with a decrease in $\mathrm{Re}, \mathrm{Nu}$ increases faster than for the case characterized with a reduction in Corrugation diameter. A contrasting behavior is observed in the context of variation of $\mathrm{Nu}$ with the Longitudinal Pitch. This because $\mathrm{Nu}$ in the present 
work is calculated from a heat transfer coefficient that is evaluated with reference to the bare surface, which increases continuously with increase in Diameter.

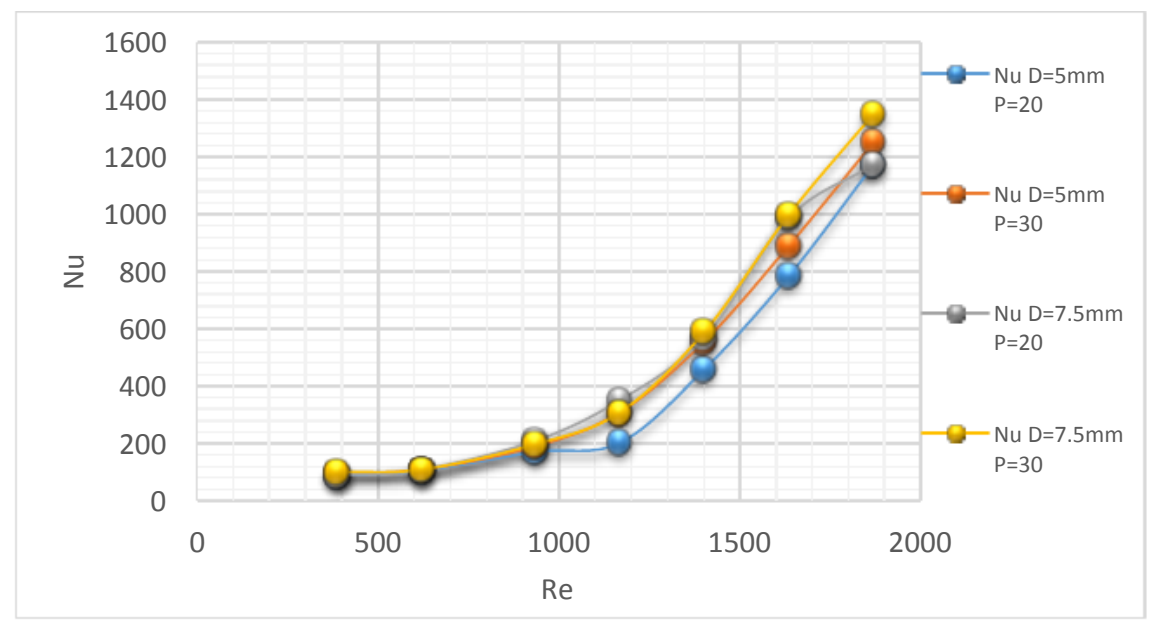

Figure $7 \mathrm{Nu}$ of Corrugated tube heat exchanger with various corrugated tube configurations.

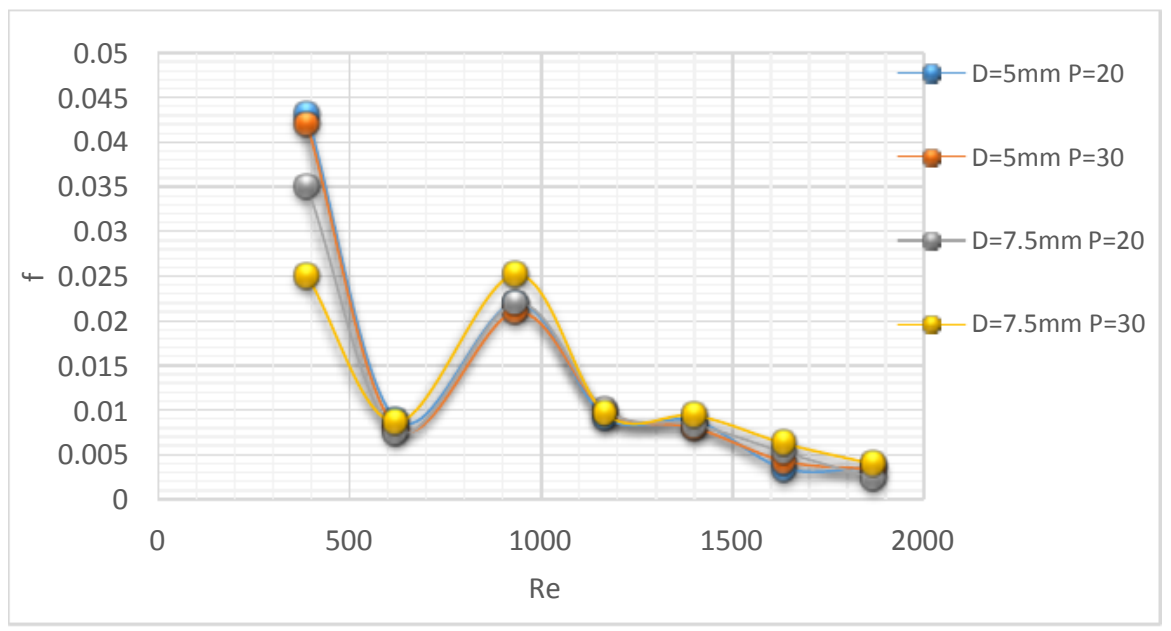

Figure $8 f$ of corrugated inner tube heat exchanger

The $\mathrm{f}$ variations presented in Fig. 8 confirm such propositions. Where Pressure drop $\Delta p$ is calculated by ansys output manager as shown in Fig. 8 whereas mean fluid velocity of flow is setup in the ansys solution setup. However, Fig. 8 show that the behavior of $\mathrm{f}$ in response to changes in $\mathrm{Re}$ is quite like the $\mathrm{f}$ behavior of the corresponding smooth tube. A completely different behavior can be observed regarding the variation of $f$ with $R e$. whereas in the corresponding twisted tape arrangement $f$ increases with a decrease in Re.

The effect of the corrugation on the flow behavior can be observed when the temperature contours are represented in a region close to the contraction and expansion of the tube. At the downstream side of the corrugation, velocity is reduced, due to in this region the pressure slightly increases and prorogues an unfavorable pressure gradient that caused flow separation. 


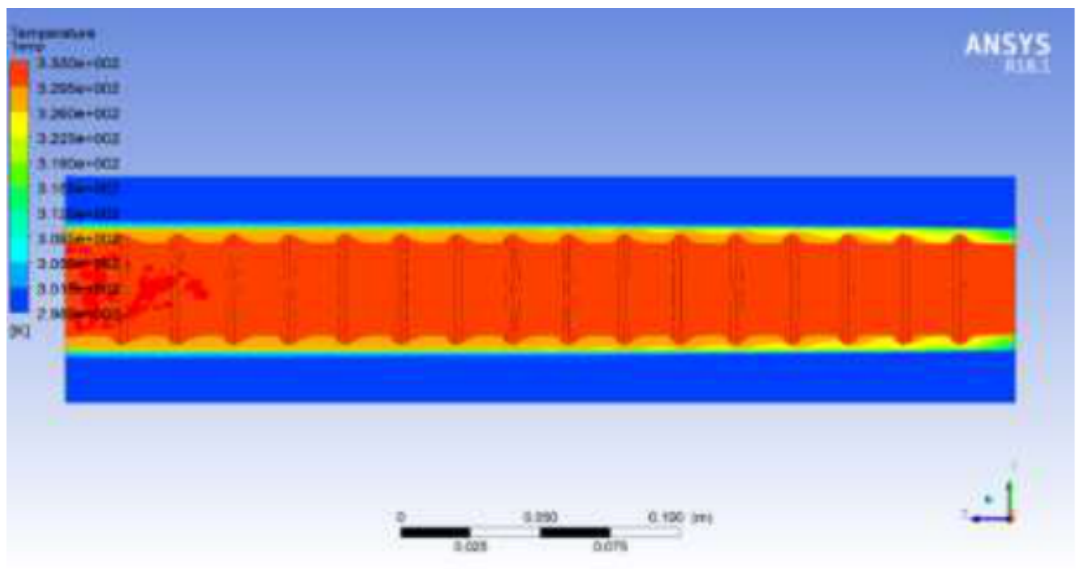

Figure 9 Temperature contours of corrugated tube

\section{CONCLUSIONS}

Corrugated Tube causes significant rise in heat transfer but less than pin fins. Comparatively low pressure drop. Heat transfer rate increases with corrugation diameter for Corrugation diameter 7.5 and corrugation pitch $30 \mathrm{~mm}$, heat transfer is more and is due to enhancement of flow recirculation in inner tube and this causes at lower Reynolds number.

Although dimensionless parameters for heat transfer $(N u)$ and pressure drop $(\Delta p)$ are very important for the scaling of the results of the heat exchanger with similar geometries, comparison of the performances of different heat transfer surfaces. Heat transfer and pressure drop compared with enhanced surfaces about 14\% - 18\%.

Pin Fin heat transfer surfaces are characterized by much higher heat transfer rates. Heat transfer rate increases with number of Pin Fins. But influenced by fin spacing and fin dia. the pressure drop is also increasing.

Remarkable improvement in Heat transfer rate with corrugated tube heat exchanger. This type of Heat exchangers can be used in waste heat recovery applications like in Power plants, food processing units and HVAC applications.

\section{REFERENCES}

[1] Wei Wang, Yaning Zhang, Yongji Li, Huaizhi Han, Bingxi Li 'Multi-objective optimization of turbulent heat transfer flow in novel outward helically corrugated tubes' Applied Thermal Engineering, ATE 11601 vol.96, pp.387-394. 2017

[2] H. S. Dizaji, S. Jafarmadar, S. Asaadi "Experimental exergy analysis for shell and tube heat exchanger made of corrugated shell and corrugated tube", International Journal of Experimental Heat Transfer, Thermodynamics and Fluid Mechanics, (2016).

[3] Xu Jin, Zhang Wen, Liu Weidong Li Yan, Tian Xinshou, Liu Chao, Wei Linjun, "Study on the Driving Force and Challenges of Developing Power Grid with High Penetration of Renewable Energy", IEEE Transportation Electrification Conference and Expo, Asia-Pacific (ITEC Asia-Pacific), 2017

[4] M.A. Gómez, J. Collazo, J. Porteiro, J.L. Míguez 'Numerical study of the thermal behaviour of a water heater tank with a corrugated coil', International Journal of Heat and Mass Transfer, Vol. no. 122 (2018) pp.574-586 
Analysis of Different Heat Transfer Augmentation Configurations of Heat Exchangers for Industrial Waste Heat Recovery Application

[5] H. S. Dizaji, S. Jafarmadar, F. Mobadersani 'Experimental studies on heat transfer and pressure drop characteristics for new arrangements of corrugated tubes in a double pipe heat exchanger', International Journal of Thermal Sciences, Vol. no. 96 (2015) pp.211-220

[6] J.I. Córcoles-Tenderoa, J.F. Belmonte, A.E. Molina, J.A. Almendros-Ibáñez 'Numerical simulation of the heat transfer process in a corrugated tube' International Journal of Thermal Sciences Vol. No. 126 (2018) pp.125-136

[7] Fabio Bozzoli, Luca Cattani, Sara Rainieri, 'Effect of wall corrugation on local convective heat transfer in coiled tubes' International Journal of Heat and Mass Transfer Vol. no. 101 (2016) pp. 76-90

[8] Rajendra N. Todkar, P.E.Chaudhari and U.M.Shirsat, Waste Heat Recovery to Increase Boiler Efficiency Using Bagasse as Fuel, International Journal of Mechanical Engineering and Technology (IJMET).Volume: 5, Issue: 2, 2014, Pages: 115-121.

[9] Experimental Investigation of Waste Heat Recovery System for Domestic Refrigerator, Tanaji Balawant Shinde, Shailendra V. Dhanal, Shirish S. Mane, International Journal of Mechanical Engineering and Technology (IJMET), Volume 5, Issue 8, August (2014), pp. 73-83

[10] Inakollu Bhanu Harsha, Kasyap Addepalli and K Karunamurthy, Heat Transfer Augmentation on Ic Engine Waste Heat Recovery System, International Journal of Mechanical Engineering and Technology 9(1), 2018. pp. 924-933.

[11] Norris, R. H., Spofford, W. A, High-Performance Fins for Heat Transfer, ASME, Vol. 64, 1942, pp. 489-496

[12] Inakollu Bhanu Harsha, Kasyap Addepalli and K Karunamurthy, Heat Transfer Augmentation on Ic Engine Waste Heat Recovery System, International Journal of Mechanical Engineering and Technology 9(1), 2018. pp. 924-933.

[13] Kays, W. M. and London, A. L. "Heat-Transfer and Friction Characteristics for Gas Flow Normal to Tube Banks - Use of a Transient-Test Technique", Transactions of ASME, Vol. 76, pp. 387-396. 1954 